Article

\title{
Enhancement of the Neuroprotective Effect of Fermented Spirulina maxima Associated with Antioxidant Activities by Ultrasonic Extraction
}

\author{
Woon Yong Choi ${ }^{1}$, Do Hyung Kang ${ }^{2}$, Soo-Jin Heo ${ }^{2}$ and Hyeon Yong Lee ${ }^{3, *}$ \\ 1 Department of Medical Biomaterials Engineering, Kangwon National University, Chuncheon 24341, Korea; \\ cwy1012@hanmail.net \\ 2 The Jeju International Marine Science Center for Research \& Education, Korea Institute of Ocean Science and \\ Technology (KIOST), Jeju 49111, Korea; dohkang@kiost.ac.kr (D.H.K.); sjheo@kordi.re.kr (S.-J.H.) \\ 3 Department of Food Science and Engineering, Seowon University, Cheongju 28674, Korea \\ * Correspondence: hyeonl@seowon.ac.kr; Tel.: +82-43-299-8471
}

Received: 9 November 2018; Accepted: 29 November 2018; Published: 3 December 2018

\begin{abstract}
This study is the first demonstration of the neuroprotective activity of the marine alga, Spirulina maxima, fermented by Lactobacillus plantarum HY-08, which was freshly isolated from fermented vegetables. The combined process of the fermentation with ultrasonic extraction at $40 \mathrm{kHz}$ for $4 \mathrm{hr}$ greatly increased the amounts of $\beta$-carotene in the extract up to $1.62 \mathrm{mg} / \mathrm{g}$, along with a high extraction yield of $18.26 \%$, compared to $1.03 \mathrm{mg} / \mathrm{g}$ and $12.8 \%$ from ultrasonic extraction itself, and even much higher than $0.81 \mathrm{mg} / \mathrm{g}$ and $10.6 \%$ from conventional water extraction. It was also proved that the neuroprotective activities of the extract were enhanced possibly by higher contents of $\beta$-carotene in the extract, compared to those from water extraction or ultrasonic extraction itself. This extract was found to have strong antioxidant properties, with 49.01\% 1,1-diphenyl-2-picrylhydrazyl (DPPH) radical scavenging activity, which resulted in 90.30\% neuroprotective activity. Specifically, the fermented extract markedly enhanced the brain-derived neurotrophic factor (BDNF)/p-CREB signaling pathways, which can effectively prevent memory impairment in mice caused by oxidative stress. $\beta$-Carotene also increased the expression of $p$-CREB and BDNF, and a mechanism of their upregulation by $\beta$-carotene is first proposed in this study. It can be concluded that the strong neuroprotective effect of the extract was markedly influenced by the antioxidant activities, due to the synergistic effects of high amounts of $\beta$-carotene and other biologically active substances in the extract that can be obtained by lactic acid fermentation, combined with ultrasonic processing.
\end{abstract}

Keywords: Spirulina maxima; fermentation; ultrasound extraction; neuroprotective effects

\section{Introduction}

Dementia is a degenerative brain disease characterized by a decline in learning, and there is a considerable increase of social interest in its prevention and treatment [1]. In general, the mechanisms underlying the phenomena of the decline in memory and cognitive functions have been understood to be an excessive accumulation of amyloid $\beta$ protein in the brain [2]. In additions to this, neurological degeneration resulting from nerve cell damage occurring during the decomposition of acetylcholine (ACh) by acetylcholinesterase (AChE) has also been considered to be a major mechanism that is associated with dementia [2,3]. Prolyl endopeptidase (PEP) is a protease that is known to be highly involved in the generation of amyloid $\beta$ protein, and it digests proline, and it is one of key neuropeptides in the cerebral cortex of the brain [4,5]; therefore, PEP inhibitors have been developed as therapeutic agents to overcome declines in memory and cognitive function. In addition, several 
chemicals that act as acetylcholinesterase inhibitors, such as donepezil, rivastigmine, and galantamine, have also been developed to improve memory in dementia patients. However, these chemicals have demonstrated side effects such as hepatotoxicity, vomiting, diarrhea, and gastrointestinal disorders. Therefore, research has been actively conducted to develop therapeutic agents from natural resources to replace these medicines [6-8]. For this purpose, multiple studies have been conducted to develop health functional foods that help to improve cognitive function or memory impairment, such as Korean angelica roots, ginkgo leaves, and Codonopsis lanceolata [9-11]. The primary mechanism of these plants in enhancing cognitive function has been found to be their strong antioxidant activities, effectively inhibiting both oxidative stress and free radical generation [9-11]. However, no effective functional food that helps to improve cognitive function or memory impairment has been developed from marine resources.

The marine microalga Spirulina maxima, with a high antioxidant activity, has been shown to have various biological effects, including anticancer, anti-inflammatory, detoxification, and anti-cholesterol activities [12,13]. These activities of S. maxima stem from biologically active substances such as C-phycocyanin (C-PC), chlorophyll, carotenoid, novel sulfated polysaccharides, and vitamin B12 [14-16]. However, C-PC and chlorophyll, which are major bioactive components in Spirulina, have the disadvantage of being easily broken down by light and high temperatures during conventional processing $[17,18]$. Most conventional methods of processing S. maxima would inevitably be affected by physical factors such as exposure to sunlight, oxygen, and high temperatures [19]. In addition to these difficulties, the utilization of the fermentation process has not been employed to process S. maxima, and except for kelp, fermentation has seldom been used for marine microalgae, even though lactic acid fermentation has been widely employed to develop other functional food materials [20]. Among bacteria, the lactic acid bacterium has been the most commonly used for the fermentation of functional foods. In general, the fermentation process has been proven to increase the biological activity of this bacteria, including its anticancer, immunological enhancement, and antibacterial activities. Recent studies have also reported that lactic acid bacteria have antioxidant and whitening effects [21]. S. maxima has been fermented by lactic acid bacteria isolated from fermented vegetables (i.e., kimchi) (MG547899, National Center for Biotechnology Information, GenBank, USA) in an effort to derive greater memory improvement effects [21]. To ensure the enhancement of its biological activities, in the current study, the fermentation of S. maxima used a nonthermal process and ultrasonic extraction in combination with lactic acid fermentation, which enabled the effective elution of heat-sensitive bioactive substances such as $\beta$-carotene from the S. maxima. An ultrasonic process has been shown to be effective in extracting heat-labile components from many natural resources at relatively low process temperatures [19]. Therefore, utilizing the advantages of such a combined process, the neuroprotective activities associated with the antioxidant activities of S. maxima extracts were evaluated to explore new areas for the application of the marine microalga, S. maxima.

\section{Materials and Methods}

\subsection{Preparation of Fermented S. maxima Fermentation}

The marine alga Spirulina maxima used in this study was supplied by the Korea Institute of Ocean Science \& Technology (KIOST, Jeju, Korea). To prepare the S. maxima fermentation extract, $100 \mathrm{~g}$ of S. maxima powder was mixed with $1 \mathrm{~L}$ of distilled water containing $0.5 \%(\mathrm{w} / \mathrm{v})$ yeast extract, $1 \%$ peptone, $2 \%$ glucose, $0.01 \%$ magnesium sulfate, $0.005 \%$ manganese sulfate, $0.2 \%$ potassium phosphate and $0.1 \%(\mathrm{v} / \mathrm{v})$ polysorbate 80 (All chemicals were purchased from Sigma, St. Louis, MO, USA). The culture medium was inoculated with $1 \times 10^{5} \mathrm{CFU}$ of Lactobacillus plantarum HY-08 (Accession number: MG547899) as an initial seed volume, which was incubated at $37{ }^{\circ} \mathrm{C}$ for four days under anaerobic conditions. The whole culture broth was then treated by an ultrasonic extractor (AUG-R3-900, ASIA ULTRASONIC, Gyeonggi-do, Korea). Based on the previous research, we set the ultrasound conditions as follows: $40 \mathrm{kHz}$ for $6 \mathrm{hr}$ at room temperature [22]. To prepare two different control 
samples, $100 \mathrm{~g}$ of $S$. maxima powder was first added to $1 \mathrm{~L}$ of distilled water and extracted at $100{ }^{\circ} \mathrm{C}$ for $12 \mathrm{~h}$, and the ultrasonic extract was prepared only by ultrasonic extractor treatment (AUG-R3-900, ASIA ULTRASONIC, Gyeonggi-do, Korea) at $40 \mathrm{kHz}$ for $12 \mathrm{hr}$ at room temperature. Both of the obtained extracts were filtered using a vacuum filtration pump (KNF Laboport Pressure Pump, Cole-Parmer, Vernon Hills, IL, USA) and 20-25 $\mu \mathrm{m}$ filter paper from Whatman Co. (Piscataway, NJ, USA). The filtered extracts were concentrated using a rotary vacuum evaporator (Rotary Vacuum Evaporator N-N series, EYELA, Rikakikai Co., Tokyo, Japan), and powdered using a freeze dryer (PVTFA 10AT, ILSIN, Suwon, Korea).

\subsection{Determination of $\beta$-Carotene Content in the Extracts}

The amount of $\beta$-carotene in the S. maxima extracts from the three different processes was analyzed using high-performance liquid chromatography (HPLC, Dionex 3000, Dionex Co., Sunnyvale, CA, USA) with a $\mathrm{C}_{18}$ column (Jupiter $\mathrm{C}_{18}$ column, $4.6 \times 250 \mathrm{~mm}, 5 \mu \mathrm{m}, 300 \mathrm{~A}$, 00G-4053-E0, Phenomenex, CA, USA). In the analysis, the mobile phases of solvent A ( $60 \%$ methanol, $10 \%$ butanol, $30 \%$ water) and solvent B ( $89.5 \%$ methanol, $10 \%$ butanol, $0.5 \%$ water) were flowed under gradient conditions of 0-8 $\min$ (75:25), 8-50 $\min$ (90:10), 50-55 $\mathrm{min}$ (90:10), 55-57 $\mathrm{min}$ (75:25), and 57-65 $\mathrm{min}$ (75:25) at a flow velocity of $1.0 \mathrm{~mL} / \mathrm{min}$, along with a standard $\beta$-carotene (C4582, Sigma-Aldrich, St. Louis, MO, USA). The analysis was conducted by simultaneously evaluating the wavelengths $452 \mathrm{~nm}$ and $325 \mathrm{~nm}$ [17].

\subsection{Measurement of the DPPH Free Radical-Scavenging Activity of the Extracts}

The antioxidant activity of the extracts was evaluated by measuring $\alpha, \alpha$-diphenyl- $\beta$ picrylhydrazyl (DPPH) free radical-scavenging activity, which is a representative method for measuring the antioxidant activity of the extracts. In a 96-well plate, $200 \mu \mathrm{L}$ of a $0.1 \mathrm{mM}$ DPPH solution was prepared in ethanol as a solvent, and $80 \mu \mathrm{L}$ of the sample at various concentrations $(0.156,0.313,0.625$, and $1.250 \mathrm{mg} / \mathrm{mL}$ ) was added. The mixtures were left unattended in a dark room at $25^{\circ} \mathrm{C}$ for $20 \mathrm{~min}$, and the absorbance was then measured at $525 \mathrm{~nm}$. The optical density was measured at $517 \mathrm{~nm}$ using a microplate reader (Thermo Fisher Scientific, Waltham, MA, USA). The relevant values were estimated as DPPH radical scavenging activity (\%) [23].

DPPH radical scavenging activity $(\%)=($ Control O.D. - Sample O.D. $) /($ Control O.D. $) \times 100$

\subsection{Measurement of the Neuroprotective Activity of the Extracts}

A 3-(4,5-dimethylthiazo-2-yl)-2,5-diphenyltetrazolium bromide (MTT) assay was performed to measure the neuroprotective activity of the extracts from the various extraction processes. First, a 96-well plate was inoculated with mouse hippocampus-derived cells (HT22, donated by Prof. Choong Je Ma, Department of Medical Biomaterials Engineering, College of Biomedical Science, Kangwon National University) at a concentration of $1.5 \times 10^{4}$ cells/well, and the cells were divided into an experimental group that was treated with glutamate at approximately $80 \%$ cell confluency, to induce apoptosis and a second group that was not treated with glutamate. The samples were treated with different concentrations ( $200 \mu \mathrm{L}$ per concentration), and the cells were cultivated for $24 \mathrm{hr}$ in a $\mathrm{CO}_{2}$ incubator. Thereafter, a MTT solution at a concentration of $5 \mu \mathrm{g} / \mathrm{mL}$ was added to each well. The supernatant was removed $4 \mathrm{hr}$ later, $10 \mu \mathrm{L}$ of acid-isopropanol $(0.04 \mathrm{~N} \mathrm{HCl}$ in isopropanol) was added to each well, and the absorbance was measured at a wavelength of $565 \mathrm{~nm}$ using a microplate reader (Tecan, Mannedorf, switzerland). The degree of neuroprotective effect of the extracts was expressed as the relative protection by estimating the ratio of the absorbance of cell growth treated with glutamate alone (control) to the absorbance of cell growth treated with glutamate and the extract [11].

\subsection{Determination of the Inhibition of ROS and $\mathrm{Ca}^{2+}$ Production from HT22 Cells}

To measure reactive oxygen species (ROS) activity, the glutamate-induced ROS in HT22 cells was measured using $2^{\prime}, 7^{\prime}$-dichlorofluorescein diacetate (DCF-DA). The HT22 cells were seeded into 
a 48 -well plate at a concentration of $4.02 \times 10^{3}$ cells/well, cultured at $37^{\circ} \mathrm{C}$ for $24 \mathrm{hr}$, treated with Trolox (positive control) and glutamate, and cultured for an additional $8 \mathrm{hr}$. Thereafter, the cells were treated with $10 \mu \mathrm{M}$ DCF-DA, cultured for $1 \mathrm{hr}$, and treated with $1 \%$ Triton X-100. The ROS activity was measured at an excitation wavelength of $488 \mathrm{~nm}$ and an emission wavelength of $530 \mathrm{~nm}$ using a fluorescence analyzer [24]. Fura-2AM was used to measure calcium ions $\left(\mathrm{Ca}^{2+}\right)$ in the HT22 cells. After treatment with either the sample, Trolox (positive control), or glutamate, the HT22 cells were treated with $2 \mu \mathrm{M}$ Fura-2AM before harvesting. Two hours later, the cells were washed with PBS and treated with $1 \%$ Triton X-100 before extraction. The calcium ions were measured at an excitation wavelength of $400 \mathrm{~nm}$ and an emission wavelength of $535 \mathrm{~nm}$ using a calcium ion fluorescence analyzer [24].

\subsection{Measurement of Glutathione Peroxidase and Glutathione Reductase Activities via Treatment of the Extracts}

First, a 96-well plate was inoculated with HT22 cells at a concentration of $1.5 \times 10^{4}$ cells/well. After incubation, 1, 10, and $100 \mu \mathrm{g} / \mathrm{mL}$ of sample and Trolox $(50 \mu \mathrm{M})$ were added to the cells and incubated for $1 \mathrm{hr}$, followed by treatment with $2 \mathrm{mM}$ glutamate. To measure the glutathione peroxidase activity, $100 \mu \mathrm{L} / \mathrm{mL}$ of the reaction mixture was well mixed with $500 \mu \mathrm{L}$ of $0.1 \mathrm{M}$ potassium phosphate buffer $(\mathrm{pH} \mathrm{7.0)}$ and $100 \mu \mathrm{L}$ of $0.24 \mathrm{U}$ glutathione, allowed to incubate for $10 \mathrm{~min}$ at $37^{\circ} \mathrm{C}$, and treated with $100 \mu \mathrm{L}$ of $1.5 \mathrm{mM}$ Nicotinamide Adenine Dinucleotide Phosphate Hydrogen (NADPH). The peroxide-independent consumption of NADPH was then measured at $340 \mathrm{~nm}$ for $1 \mathrm{~min}$ using a spectrophotometer. Next, $1 \mathrm{mM}$ potassium cyanide and $100 \mu \mathrm{L}$ of $1.5 \mathrm{mM}$ hydrogen peroxide were added to inhibit the catalase activity. The peroxide-independent NADPH concentration was determined by measuring the decrement of peroxide for 3 min to assess the enzyme activity. The enzyme activity of glutathione was measured at $412 \mathrm{~nm}$ after adding $1 \mathrm{mM}$ NADPH to $1.0 \mathrm{~mL}$ of a solution containing $100 \mu \mathrm{g}$ of the sample, $0.1 \mathrm{M}$ sodium phosphate buffer (pH 7.6), $1 \mathrm{mM}$ EDTA, $1 \mathrm{mM}$ GSSG and $0.6 \mathrm{mM} 5,5^{\prime}$-dithiobis-2-nitrobenzoic acid (DTNB). The activity of glutathione reductase was also measured by calculating the ratio of the production of 2-nitro-3-thiobenzoic acid from DTNB during the reduction of glutathione $[25,26]$.

\subsection{Western Blot Analysis of BDNF (Brain-Derived Neurotrophic Factor) and p-CREB (cAMP-Responsive Element-Binding Protein) Gene Expression Induced by the Extract}

Proteins were quantitated from HT22 cells that had been treated with the extracts, and the proteins were separated by electrophoresis on a $12 \%$ polyacrylamide gel, and transferred to a polyvinylidene fluoride (PVDF) membrane. The membrane was blocked with $5 \%$ skim milk solution for $1 \mathrm{~h}$, and incubated with primary antibodies BDNF (SC-546, Santa Cruz Biotechnology, Dallas, TX, USA), p-CREB (SC-81486, Santa Cruz Biotechnology, Dallas, TX, USA) at $4{ }^{\circ} \mathrm{C}$ for $24 \mathrm{hr}$. The membrane was then washed three times using TBST (Tris-buffered saline with $0.1 \%$ Tween-20), and incubated with the secondary antibody at room temperature for $1 \mathrm{hr}$. The separated proteins were observed using an LAS 4000 mini system (GE Healthcare, Richmond, VA, USA) [27,28].

\subsection{Statistical Analysis}

The data are expressed as the mean $\pm \mathrm{SD}$ (standard deviation), and the mean is the average of five test results per experiment. The data were analyzed using Student's $t$-test (SAS 9.1, SAS, Cary, NC, USA). The data were also analyzed by the one-way analysis of variance (ANOVA) test, and the mean values were considered to be significantly different at $p<0.01, p<0.05$ and $p<0.1$.

\section{Results}

\subsection{Extraction Yield and $\beta$-Carotene Content of the Extracts}

HPLC analysis exhibited the highest $\beta$-carotene content in the S. maxima fermentation products. The concentrations of $\beta$-carotene in individual processes were analyzed, and the results are presented in Table 1 and Figure 1. 
Table 1. Estimation of $\beta$-carotene content from $S$. maxima in the extracts from various extraction conditions.

\begin{tabular}{ccc}
\hline Extraction Process & $\beta$-Carotene Content $(\mathrm{mg} / \mathrm{g})$ & Extraction Yield (\%) \\
\hline $\mathrm{FE}^{1}$ & $1.62 \pm 0.22$ & $18.26 \pm 1.93$ \\
$\mathrm{WE}^{2}$ & $0.81 \pm 0.13$ & $10.60 \pm 1.44$ \\
$\mathrm{UE}^{3}$ & $1.03 \pm 0.34$ & $12.77 \pm 1.68$ \\
\hline
\end{tabular}

${ }^{1} \mathrm{FE}$ : Fermented Spirulina maxima with ultrasonic extraction process at room temperature for $6 \mathrm{hr} .{ }^{2} \mathrm{WE}$ : Conventional water extraction at $100{ }^{\circ} \mathrm{C}$ for $12 \mathrm{hr} .{ }^{3}$ UE: Ultrasonic extraction process at room temperature for $6 \mathrm{hr}$.

(a)

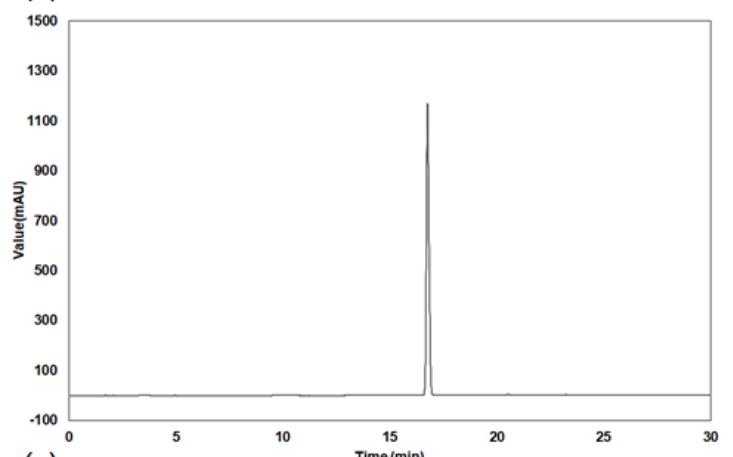

(c)

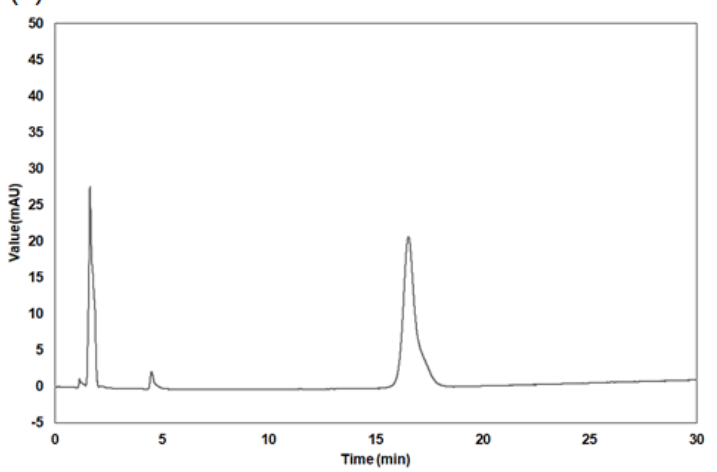

(b)

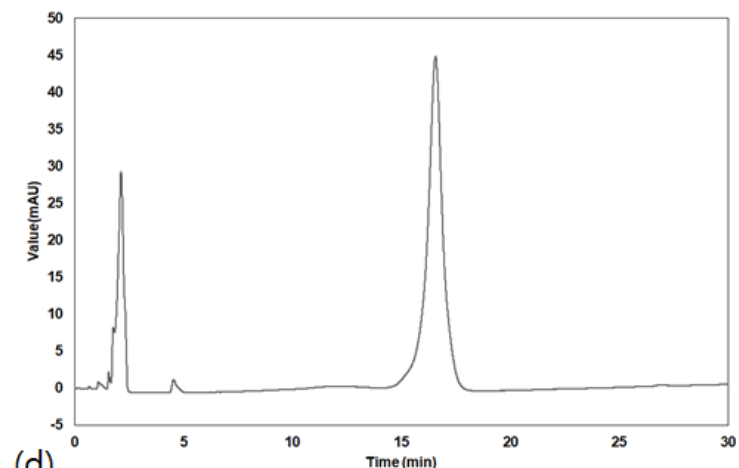

(d)

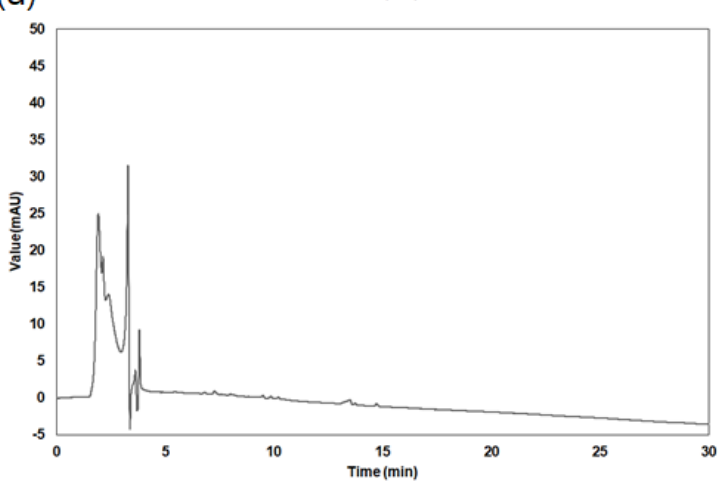

Figure 1. High-performance liquid chromatography (HPLC) chromatograms of (a) $\beta$-carotene standard (b) fermented Spirulina maxima by Lactobacillus plantarum HY-08 with ultrasonic extraction process, (c) S. maxima extracted by only ultrasonic extraction process, (d) S. maxima extracted by conventional water extraction.

To identify the enhancement of the $\beta$-carotene content in the S. maxima extracts, three different extraction processes (ultrasonic, conventional hot water, and fermentation process with ultrasonic extraction processes) were compared and analyzed. The $\beta$-carotene content of the S. maxima fermentation products was estimated as $1.62 \mathrm{mg} / \mathrm{g}$, and the lowest $\beta$-carotene content at $0.81 \mathrm{mg} / \mathrm{g}$ was observed in the hot water extract. A $\beta$-carotene content of $1.03 \mathrm{mg} / \mathrm{g}$ was obtained when only the ultrasonic process was applied, as well as $0.06 \mathrm{mg} / \mathrm{g}$ of negligible amount of $\beta$-carotene in the culture broth of only the fermentation as another control (data not shown). This result clearly indicate that a larger quantity of $\beta$-carotene was eluted through the fermentation with ultrasonic processing, possibly by first softening the cell walls of Spirulina, and bioconversion during the fermentation and then accelerating the elution of $\beta$-carotene in applying ultrasonic treatment. The highest extraction yield, at approximately $18.26 \%$, was obtained from the $S$. maxima fermentation products, and the lowest yield $(10.66 \%)$ was obtained from hot water extraction, showing similar trends in the amount of $\beta$-carotene in the extracts. Interestingly, the HPLC chromatogram of the extract from both fermentation and ultrasonic extraction contained more small peaks, which could represent the existence of other components in the extracts that are associated with the highest extraction yield. Therefore, it was shown that the fermentation extraction process was effective in processing the marine alga, S. maxima. 


\subsection{Comparison of Antioxidant and Neuroprotective Activities of $\beta$-Carotene and the Fermented S. maxima Extract}

To identify the antioxidant effects of the S. maxima fermentation products based on the above results, the DPPH activities were measured, and the results are presented in Figure 2. In the case of the hot water extract and ultrasonicated extracts, the highest DPPH free radical scavenging activity (approximately $31.98 \%$ and $35.12 \%$, respectively) were observed at the highest concentration of $1.0 \mathrm{mg} / \mathrm{mL}$. On the other hand, the S. maxima fermentation products showed a DPPH free radical scavenging activity of approximately $49.01 \%$ at the same dosage, indicating that the S. maxima fermentation products exhibited the highest antioxidant activity. Therefore, the neuroprotective activities were measured based on the excellent antioxidant effect of the S. maxima fermentation products analyzed, as described above.

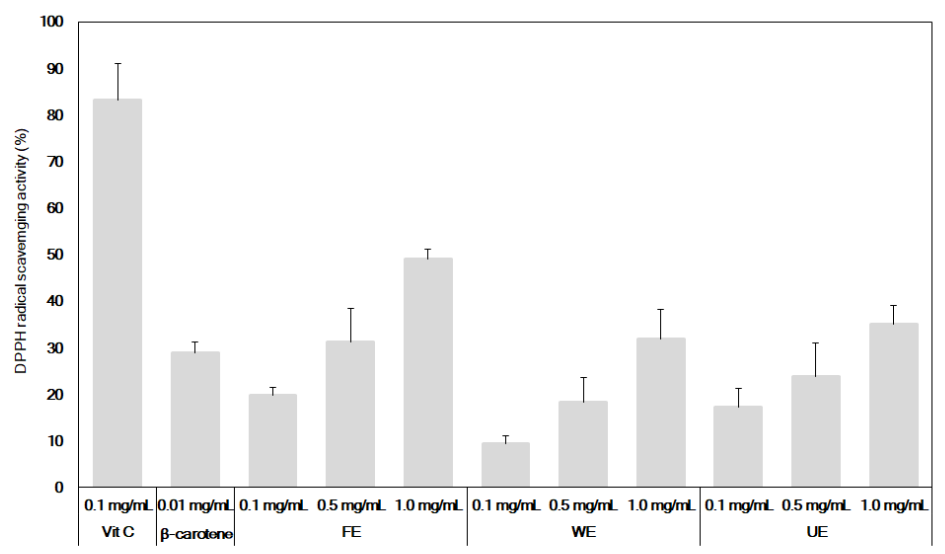

Figure 2. Comparison of the DPPH radical scavenging activity of several extraction processes. FE: fermented Spirulina maxima by Lactobacillus plantarum HY-08, WE: S. maxima extract by conventional extraction conditions. UE: Ultrasonication process.

The neuroprotective activities were compared and analyzed in the HT22 cells. The results are presented in Figure 3.

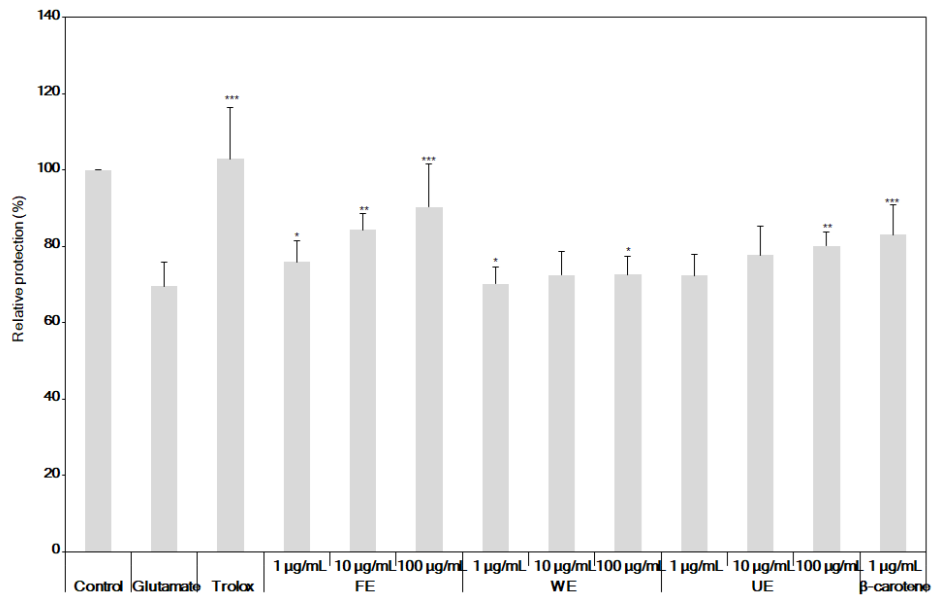

Figure 3. The neuroprotective activities of fermented Spirulina maxima on glutamate-induced oxidative stress in HT22 cells. The values shown are the mean. ${ }^{*} p<0.05,{ }^{* *} p<0.01$ and ${ }^{* *} p<0.001$ show significant differences in comparison to the glutamate group $(n=6)$.

The neuroprotective activities were measured in HT22 cells treated with glutamate under the extraction conditions of $12 \mathrm{hr}$ at $100{ }^{\circ} \mathrm{C}$, which is a hot water extraction process, and these results indicated neuroprotective activities of $70.10 \%, 72.39 \%$, and $72.60 \%$ in treating $1 \mu \mathrm{g} / \mathrm{mL}$, 
$10 \mu \mathrm{g} / \mathrm{mL}$, and $100 \mu \mathrm{g} / \mathrm{mL}$ of the WE, respectively. In the case of the S. maxima fermentation products, the neuroprotective activities in the glutamate-treated HT22 cells were shown to be $75.84 \%, 84.33 \%$, and $90.30 \%$, depending on the treatment concentrations, and in the case of the ultrasonicated extracts, the neuroprotective activities were shown to be $72.30 \%, 77.60 \%$, and $80.12 \%$, depending on the treatment concentrations. The fermented extracts exhibited markedly increased neuroprotective activities compared to those of the $S$. maxima extracts obtained through conventional extraction methods. In particular, the result of treatment of the glutamate-treated HT22 cells with $\beta$-carotene from S. maxima at a concentration of $1 \mu \mathrm{g} / \mathrm{mL}$, showed a high neuroprotective activity of approximately $82.96 \%$, indicating that the $\beta$-carotene contained in the S. maxima directly affected the neuroprotective activity.

\subsection{Neuroprotective Effects of the Fermented S. maxima Extract against Brain Oxidative Stress}

The results of the ROS formation inhibitory activity of the S. maxima fermentation products are presented in Figure 4.

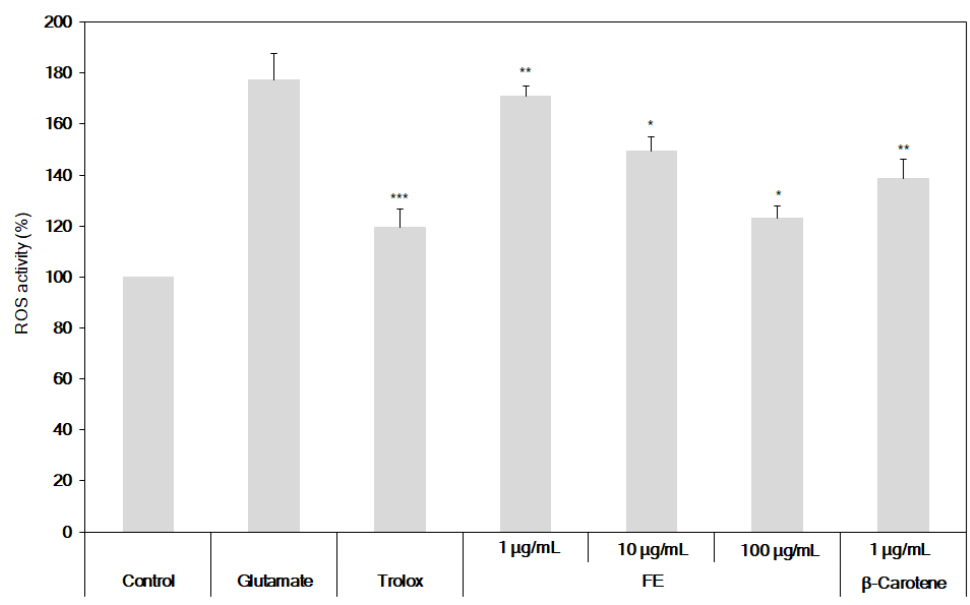

Figure 4. The effect of fermented Spirulina maxima on glutamate-induced reactive oxygen species (ROS) production in HT22 cells. The values shown are the mean. ${ }^{*} p<0.05,{ }^{* *} p<0.01$ and ${ }^{* * *} p<0.001$ show significant differences in comparison to the glutamate group $(n=6)$.

In the case of the S. maxima fermentation products, as the concentration increased, the ROS activity was significantly inhibited from $170.96 \%$, to $149.27 \%$ and $123.26 \%$. In the case of $\beta$-carotene, the ROS activity was significantly inhibited to $138.59 \%$ when $1 \mu \mathrm{g} / \mathrm{mL} \beta$-carotene was administered. The levels of glutathione, glutathione reductase, and glutathione peroxidase, which inhibit ROS formation, are presented in Table 2.

Table 2. The effect of fermented Spirulina maxima on the levels of glutathione, glutathione reductase, and glutathione peroxidase in HT22 cells treated by $2 \mathrm{mM}$ glutamate.

\begin{tabular}{ccccc}
\hline Sample & $\begin{array}{c}\text { Treated Concentration } \\
(\boldsymbol{\mu} \mathbf{g} \mathbf{m L})\end{array}$ & $\begin{array}{c}\text { Glutathione } \mathbf{( \%} \\
\text { of Control) }\end{array}$ & $\begin{array}{c}\text { Glutathione Reductase } \\
(\% \text { of Control) }\end{array}$ & $\begin{array}{c}\text { Glutathione Peroxidase } \\
(\% \text { of Control) }\end{array}$ \\
\hline Control & - & 100.00 & 100.00 & 100.00 \\
\hline Trolox & $50 \mu \mathrm{M}$ & $91.88 \pm 8.90$ & $93.32 \pm 7.21$ & $91.26 \pm 1.67$ \\
\hline Fermented & 1 & $51.02 \pm 3.31$ & $61.42 \pm 8.23$ & $67.94 \pm 5.50$ \\
$\begin{array}{c}\text { Spirulina maxima } \\
\text { extracts }\end{array}$ & 10 & $63.76 \pm 5.18$ & $70.23 \pm 4.49$ & $75.07 \pm 7.36$ \\
\hline$\beta$-carotene & 100 & $80.38 \pm 9.30$ & $81.27 \pm 5.11$ & $80.33 \pm 7.18$ \\
\hline
\end{tabular}

According to the results in Table 2, when treating the S. maxima fermentation extracts along with $2 \mathrm{mM}$ of glutamate, the production of glutathione was significantly increased from $51.02 \%$ to $63.76 \%$ and $80.38 \%$ as the treatment dosages were increased, and even similarly, to $91.88 \%$ from treatment 
with a strong antioxidant, Trolox, as a positive control. However, in the case of treating $1 \mu \mathrm{g} / \mathrm{mL}$ of $\beta$-carotene, its activity was observed to be approximately $47.73 \%$, which was lower than that of treating $1 \mu \mathrm{g} / \mathrm{mL}$ of the fermented extract. In addition to the production of glutathione, the enzyme activities of both glutathione reductase and glutathione peroxidase were also significantly increased as the concentrations of the $S$. maxima fermentation products increased. These results strongly support our data that the fermented extracts have good antioxidant activities, which can work to improve the enzyme activities that are associated with the glutathione production pathway. Therefore, this sequential process represents antioxidant recovery reaction in memory-impaired brain systems. The measurements of the intracellular $\mathrm{Ca}^{2+}$ concentration, which induce ROS activity within the cells, are shown in Figure 5 .

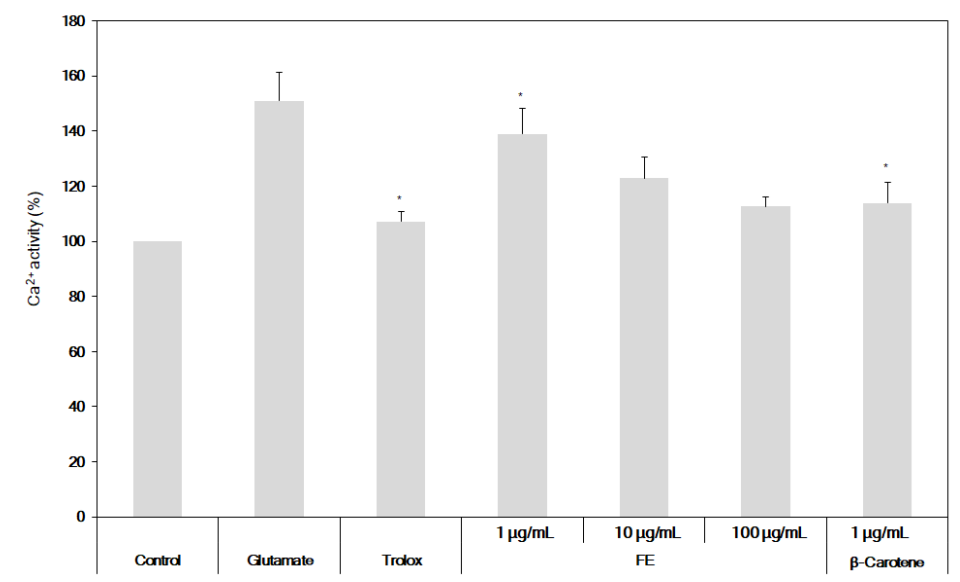

Figure 5. The effect of fermented Spirulina maxima on the level of $\mathrm{Ca}^{2+}$ in HT22 cells. The values shown are the mean. ${ }^{*} p<0.05$ show significant differences in comparison to the glutamate group $(n=6)$.

Upon treating the S. maxima fermentation products, the calcium concentration significantly decreased, from $138.98 \%$ to $122.85 \%$ and $112.63 \%$, as the concentration of the $S$. maxima fermentation products increased. The effect of $\beta$-carotene in reducing the calcium concentration was approximately $113.93 \%$, which was close to the effect of treating $100 \mu \mathrm{g} / \mathrm{mL}$ of the fermented extract.

\subsection{Enhancement of BDNF/p-CREB Signaling Pathways in Glutamate-Induced, Oxidatively Stressed HT22} Cells with the Fermented S. maxima Extract

The results of the measurement of the BDNF/p-CREB signaling pathway of BDNF and the parent transcription factor p-CREB from the S. maxima fermentation are presented in Figure 6.

According to the results, the BDNF expression levels in the experimental group treated with the S. maxima fermentation products increased to 0.91. In addition, the BDNF expression levels in the experimental group treated with $\beta$-carotene increased to 0.85 . The $\mathrm{p}$-CREB expression levels in the experimental group treated with the $S$. maxima fermentation products increased to 1.22 . Therefore, to accurately measure the induction of the signaling pathways by the S. maxima fermentation products, according to the gene expression, the BDNF/ $\mathrm{p}-\mathrm{CREB}$ expression ratio was measured. The results are presented in Table 3. The p-CREB/BDNF expression ratio was determined to be approximately 1.338, indicating that the $\mathrm{p}$-CREB expression was higher.

Table 3. Effect of neuroprotective activities of fermented Spirulina maxima on the BDNF/p-CREB expression ratio in HT22 cells.

\begin{tabular}{cc}
\hline Extraction Process & p-CREB/BDNF Expression Ratio \\
\hline $\mathrm{FE}^{1}$ & 1.338 \\
$\beta$-carotene & 1.055 \\
\hline${ }^{1}$ FE: Fermented Spirulina maxima with ultrasonication process at $25^{\circ} \mathrm{C}$ for $6 \mathrm{hr}$
\end{tabular}


(a)

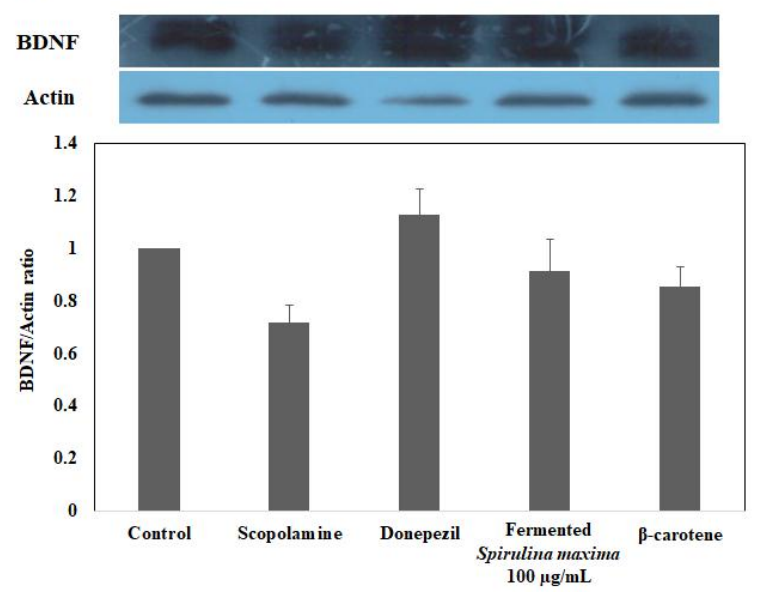

(b)

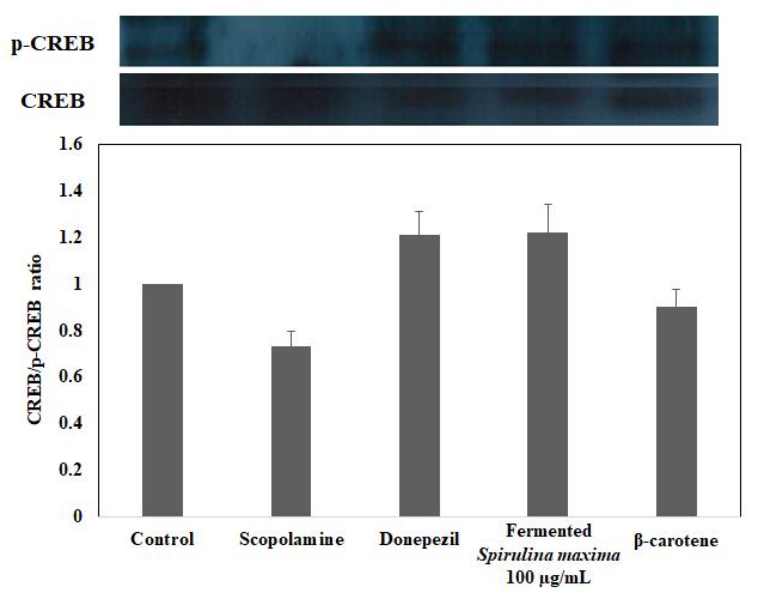

Figure 6. (a) Brain-derived neurotrophic factor (BDNF) and (b) p-CREB expression levels from fermented Spirulina maxima after glutamate-induced ROS production in HT22 cells.

\section{Discussion}

Among the many biologically active substances in S. maxima, $\beta$-carotene was selected and analyzed for content determination in the extracts of $S$. maxima from various extraction processes because it is known to be effective for improving cognitive ability and memory [29]. Although a fat-soluble $\beta$-carotene is normally extracted using an organic solvent such as methanol, ethanol, or acetone, water should be used in this case, as organic solvents are not suitable for use in fermentation [30]. Therefore, the concentrations of $\beta$-carotene in the extracts processed with only hot water and from ultrasonic extraction with water solvent should also be measured as controls, to compare with those from a combined process of fermentation and ultrasonic extraction [17]. The result of this work proved this combined process is effective in eluting $\beta$-carotene with water solvent. These are considered to be the first convincing results where an increase of $\beta$-carotene content from S. maxima was observed by using a combination of lactic acid fermentation and ultrasonic extraction with only water solvents, which is critically important in industrial applications, although previous reports have indicated that the $\beta$-carotene content and the content of the indicator components in natural products could be increased through fermentation [31]. It was also clearly shown that the highest antioxidant activity exhibited in the fermentation extracts can be attributed to the highest $\beta$-carotene content in the extracts from a combined process compared to the other extracts, because $\beta$-carotene has mainly worked on strong antioxidant effects in the extracts $\beta$-carotene from various processes $[29,32,33]$. Also, from previous reports of the function of $\beta$-carotene, such as a high neuroprotective activity $[29,34]$, the above results strongly indicate that the extract with high amounts of $\beta$-carotene could be expected to improve cognitive function and memory. More interestingly, the neuroprotective activities of the extracts that contained lower amounts of $\beta$-carotene performed better than when treating with pure $\beta$-carotene, possibly due to the synergistic effects between the $\beta$-carotene and other biologically active substances, along with the high extraction yield. Similar results were also shown in other works [35]. However, more detailed experiments investigating these effects are required.

$\beta$-carotene is known to be a potent antioxidant, and its strong antioxidant activity is known to be effective for ischemia treatment and neuroprotective activity $[27,29,30]$, which can result in neuroprotective effects of $S$. maxima. These features are considered to be the reasons for the high neuroprotective activity observed above $[29,34]$. Since the fermentation extracts and $\beta$-carotene showed high neuroprotective activity in the above results, it is possible to expect the correlation between the activities against oxidative stress and the neuroprotective activity, which can derive a neuroprotective mechanism that is associated with antioxidant activities, whose mechanism was also proposed in 
other works $[25,35,36]$. To confirm this hypothesis, the reduction of ROS production was also observed in this work, because this treatment induces oxidative damage, $\mathrm{Ca}^{2+}$ ions induce ROS activity, and Glutathione (GSH) inhibits ROS formation [36]. Therefore, this clearly proved that that such high ROS activity and $\mathrm{Ca}^{2+}$ concentration still led to a reduced oxidative stress in the fermentation extract is considered to be attributable to the high $\beta$-carotene content. Based on such a strong antioxidant effect, S. maxima fermentation products are considered to be effective for diverse chronic degenerative brain diseases such as Alzheimer's disease, Parkinson's disease, Huntington's disease, and stroke [29,30,36]. With regard to the BDNF/p-CREB signaling pathway for neuroprotective and memory enhancement activities, BDNF is known to produce new neurites to reinforce connections among nerve cells, and increase the number of connections to improve abilities. cAMP-responsive element-binding protein ( $\mathrm{p}-\mathrm{CREB}$ ) is a gene required in the process of learning and memorizing, and it is known to act as a parent transcription factor for BDNF expression [37]. On the other hand, $\beta$-carotene has been reported to amplify the expression of genes such as BDNF to improve depression [27]. In particular, the increase in the expression of BDNF was proven for the first time with memory improvement using $\beta$-carotene. The $\mathrm{p}$-CREB/BDNF expression ratio was 1.055, indicating that the expression of BDNF was more strongly upregulated than $\mathrm{p}-\mathrm{CREB}$, indicating that the extract has memory-improving effects, mainly by boosting up the production of BDNF, compared to the phosphorylation of CREB, and similar results were also reported elsewhere [37]. Therefore, by combining fermentation and an ultrasonic extraction process, the $S$. maxima extracts were proven to positively affect the memory-improving activity because they increased the expression of the parent transcription factor (p-CREB) and exhibited antioxidant effects, thereby increasing the expression of brain-derived neurotrophic factor (BDNF).

\section{Conclusions}

This study clearly showed, for the first time, that the extraction yield of $\beta$-carotene in the extracts of $S$. maxima was significantly increased by combining lactic acid fermentation with a nonthermal ultrasonic extraction process, using water as a solvent. This study was also the first to prove that the increase of $\beta$-carotene content in the extracts greatly enhances its neuroprotective effects by efficiently suppressing the production of ROS and intracellular calcium ions in glutamate-induced HT22 cells, in addition to enhancing glutathione synthesis enzyme activity. The overall neuroprotective effects of the extract from a combined process were considered to be strongly correlated with its strong antioxidant activities. The effects of this extract were more pronounced than those of intact Spirulina sp. or of extracts from other conventional extraction processes, such as water or ethanol extraction, possibly due to the lower yields of $\beta$-carotene in these other processes. This study also reported in detail that neuroprotective mechanisms of the extract effectively suppressed oxidative stress by the cascading effects of an initial increase in the expression of the parent transcription factor p-CREB, along with antioxidant effects, and then an induction of the expression of BDNF. A similar mechanism of $\beta$-carotene was determined to explain its neuroprotective effects, even though in general, its activities were lower than those of the extracts, due to the synergistic effects of the extract from the combined process, rather than the effect of $\beta$-carotene as a single component. Conclusively, the $S$. maxima extract from both fermentation and ultrasonic extraction processes exhibited a strong neuroprotective effect mainly caused by suppressing oxidative stress via markedly inducing the brain antioxidative pathway of BDNF/p-CREB expression in glutamate-induced HT22 cells. It was additionally revealed that the effects of the extract were closely correlated with the synergistic effects from $\beta$-carotene and other biologically active components in the extract. Therefore, the results of this work could provide useful information for upgrading the biological activities of natural resources by employing nonthermal processes of fermentation and ultrasonic extraction.

Author Contributions: W.Y.C., S.-J.H., and D.H.K. carried out all of the experiments, and H.Y.L. designed the experiments and drafted the manuscript. All authors read and approved the final manuscript.

Funding: This research was funded by [Ministry of Oceans and Fisheries, Korea] grant number [20170326]. 
Acknowledgments: This research was a part of the project titled 'Development of integrated technologies for developing biomaterials using by magma seawater', funded by the Ministry of Oceans and Fisheries, Korea (20170326).

Conflicts of Interest: The authors declare no conflict of interest.

\section{References}

1. Citron, M. Alzheimer's disease: Treatments in discovery and development. Nat. Neurosci. 2002, 5, $1055-1057$. [CrossRef] [PubMed]

2. Dawson, G.R.; Iversen, S.D. The effects of novel cholinesterase inhibitors and selective muscarinic receptor agonists in tests of reference and working memory. Behav. Brain Res. 1993, 57, 143-153. [CrossRef]

3. Murphy, M.P.; LeVine, H. Alzheimer's Disease and the $\beta$-amyloid peptide. J. Alzheimers Dis. 2010, 19, 311-328. [CrossRef] [PubMed]

4. Hannula, M.J.; Myöhänen, T.T.; Tenorio-Laranga, J.; Männistö, P.T.; Garcia-Horsman, J.A. Prolyl oligopeptidase colocalizes with $\alpha$-synuclein, $\beta$-amyloid, tau protein and astroglia in the post-mortem brain samples with Parkinson's and Alzheimer's diseases. Neuroscience 2013, 242, 140-150. [CrossRef] [PubMed]

5. Toide, K.; Shinoda, M.; Fujiwara, T.; Iwamoto, Y. Effect of a novel prolyl endopeptidase inhibitor, JTP-4819, on spatial memory and central cholinergic neurons in aged rats. Pharmacol. Biochem. Behav. 1997, 56, 427-434. [CrossRef]

6. Fukunari, A.; Kato, A.; Sakai, Y.; Yoshimoto, T.; Ishiura, S.; Suzuki, K.; Nakajima, T. Colocalization of prolyl endopeptidase and amyloid beta-peptide in brains of senescence-accelerated mouse. Neurosci. Lett. 1994, 176, 201-204. [CrossRef]

7. Takeda, A.; Loveman, E.; Clegg, A.; Kirby, J.; Picot, J.; Payne, E.; Green, C. A systematic review of the clinical effectiveness of donepezil, rivastigmine and galantamine on cognition, quality of life and adverse events in Alzheimer's disease. Int. J. Geriatr. Psychiatry 2006, 21, 17-28. [CrossRef] [PubMed]

8. Rodda, J.; Morgan, S.; Walker, Z. Are cholinesterase inhibitors effective in the management of the behavioral and psychological symptoms of dementia in Alzheimer's disease? A systematic review of randomized, placebo-controlled trials of donepezil, rivastigmine and galantamine. Int. Psychogeriatr. 2009, 21, 813-824. [CrossRef] [PubMed]

9. Yan, J.J.; Kim, D.H.; Moon, Y.S.; Jung, J.S.; Ahn, E.M.; Baek, N.I.; Song, D.K. Protection against $\beta$-amyloid peptide-induced memory impairment with long-term administration of extract of Angelica gigas or decursinol in mice. Prog. Neuropsychopharmacol. Biol. Psychiatry 2004, 28, 25-30. [CrossRef]

10. Oken, B.S.; Storzbach, D.M.; Kaye, J.A. The Efficacy of Ginkgo biloba on cognitive function in Alzheimer Disease. Arch. Neurol. 1998, 55, 1409-1415. [CrossRef] [PubMed]

11. Weon, J.B.; Lee, B.; Yun, B.R.; Lee, J.; Lee, H.Y.; Park, D.S.; Chung, H.C.; Chung, J.Y.; Ma, C.J. Memory enhancing effect of Codonopsis lanceolata by high hydrostatic pressure process and fermentation. Korean J. Pharmacogn. 2013, 44, 41-46.

12. Hosseini, S.M.; Shahbazizadeh, S.; Khosravi-Darani, K.; Mozafari, M.R. Spirulina paltensis: Food and Function. Curr. Nutr. Food Sci. 2013, 9, 189-193. [CrossRef]

13. Lee, J.C.; Hou, M.F.; Huang, H.W.; Chang, F.R.; Yeh, C.C.; Tang, J.Y.; Chang, H.W. Marine algal natural products with anti-oxidative, anti-inflammatory, and anti-cancer properties. Cancer Cell. Int. 2013, 13, 55-61. [CrossRef] [PubMed]

14. Kay, R.A. Microalgae as food and supplement. Crit. Rev. Food Sci. Nutr. 1991, 30, 555-783. [CrossRef] [PubMed]

15. Son, M.H.; Park, K.H.; Choi, A.R.; Yoo, G.; In, M.J.; Kim, D.H.; Chae, H.J. Investigation of biological activities of enzymatic hydrolysate of Spirulina. J. Korean Soc. Food Sci. Nutr. 2009, 38, 136-141. [CrossRef]

16. Yang, H.N.; Lee, E.H.; Kim, H.M. Spirulina platensis inhibits anaphylactic reaction. Life Sci. 1997, 61, 1237-1244. [CrossRef]

17. Lee, Y.J.; Kim, S.H.; Kim, J.S.; Han, J.A.; Seo, H.J.; Lim, H.J.; Choi, S.Y. Studies on simultaneous determination of chlorophyll a and b, pheophorbide a, and $\beta$-carotene in Chlorella and Spirulina products. J. Food Hyg. Saf. 2005, 20, 141-146. 
18. Yamada, T.; Sakaguchi, K. Comparative studies on Chlorella cell walls: Induction of protoplast formation. Arch. Microbiol. 1982, 132, 10-13. [CrossRef]

19. Oh, S.H.; Ahn, J.H.; Kang, D.H.; Lee, H.Y. The effect of ultrasonificated extracts of Spirulina maxima on the anticancer activity. Mar. Biotechnol. 2011, 13, 205-214. [CrossRef]

20. Eom, S.H.; Kang, Y.M.; Park, J.H.; Yu, D.U.; Jeong, E.T.; Lee, M.S.; Kim, Y.M. Enhancement of polyphenol content and antioxidant activity of brown alga Eisenia bicyclis extract by microbial fermentation. Fish. Aquat. Sci. 2011, 14, 192-197. [CrossRef]

21. Tsai, C.C.; Chan, C.F.; Huang, W.Y.; Lin, J.S.; Chan, P.; Liu, H.Y.; Lin, Y.S. Applications of Lactobacillus rhamnosus spent culture supernatant in cosmetic antioxidation, whitening and moisture retention applications. Molecules 2013, 18, 14161-14171. [CrossRef] [PubMed]

22. Choi, W.Y.; Lee, H.Y. Enhancement of Chlorophyll a Production from Marine Spirulina maxima by an Optimized Ultrasonic Extraction Process. Appl. Sci. 2018, 8, 26. [CrossRef]

23. Dietz, B.M.; Kang, Y.H.; Liu, G.; Eggler, A.L.; Yao, P.; Chadwick, L.R.; Pauli, G.F.; Farnsworth, N.R.; Mesecar, A.D.; Breemen, R.B.; et al. Xanthohumol isolated from humulus lupulus inhibits menadione-induced DNA damage through induction of quinone reductase. Chem. Res. Toxicol. 2005, 18, 1296-1305. [CrossRef]

24. Lee, J.; Weon, J.B.; Ma, C.J. Neuroprotective activity of phytosterols isolated from Artemisia apiacea. Korean J. Pharmacogn. 2014, 45, 214-219.

25. Dar, M.A.; Khan, A.M.; Raina, R.; Beigh, S.A.; Sultana, M. Effect of repeated oral administration of bifenthrin antioxidant status and acetylcholinesterase activity in brain of rats. Toxicol. Environ. Chem. 2015, 97, 961-967. [CrossRef]

26. Lee, M.R.; Moon, S.H.; Choi, A.R.; Lee, S.C.; Ahn, K.H.; Park, H.R. Neuroprotective effects of extracts from Diospyros kaki L. Peel. Korean J. Food Cookery Sci. 2011, 27, 67-73. [CrossRef]

27. Kim, N.R.; Kim, H.Y.; Kim, M.H.; Kim, H.M.; Jeong, H.J. Improvement of depressive behavior by Sweetme Sweet Pumpkin ${ }^{\mathrm{TM}}$ and its active compound, $\beta$-carotene. Life Sci. 2016, 147, 39-45. [CrossRef]

28. Ying, S.W.; Futter, M.; Rosenblum, K.; Webber, M.J.; Hunt, S.P.; Bliss, T.V.; Bramham, C.R. Brain-derived neurotrophic factor induces long-term potentiation in intact adult hippocampus: Requirement for ERK activation coupled to CREB and upregulation of Arc synthesis. J. Neurosci. 2002, 22, 1532-1540. [CrossRef]

29. Li, F.J.; Shen, L.; Ji, H.F. Dietary intakes of vitamin E, vitamin C, and $\beta$-carotene and risk of Alzheimer's Disease: A Meta-Analysis. J. Alzheimers Dis. 2012, 31, 253-258. [CrossRef]

30. Craft, N.E.; Soares, J.H. Relative solubility, stability, and absorptivity of lutein and beta-carotene in organic solvents. J. Agric. Food Chem. 1992, 40, 431-434. [CrossRef]

31. Juan, M.Y.; Chou, C.C. Enhancement of antioxidant activity, total phenolic and flavonoid content of black soybeans by solid state fermentation with Bacillus subtilis BCRC 14715. Food Microbiol. 2010, 27, 586-591. [CrossRef]

32. Sergio, A.R.P.; Robert, M.R. $\beta$-Carotene and Other Carotenoids as Antioxidants. J. Am. Coll. Nutr. 1999, 18, 426-433. [CrossRef]

33. Tsuchihashi, H.; Kigoshi, M.; Iwatsuki, M.; Niki, E. Action of $\beta$-Carotene as an Antioxidant against Lipid Peroxidation. Arch. Biochem. Biophys. 1995, 323, 137-147. [CrossRef]

34. Mitchell, J.J.; Paiva, M.; Heaton, M.B. Vitamin E and $\beta$-carotene protect against ethanol combined with ischemia in an embryonic rat hippocampal culture model of fetal alcohol syndrome. Neurosci. Lett. 1999, 263, 189-192. [CrossRef]

35. Mitchell, J.J.; Paiva, M.; Heaton, M.B. The Antioxidants Vitamin E and $\beta$-Carotene Protect Against Ethanol-Induced Neurotoxicity in Embryonic Rat Hippocampal Cultures. Alcohol 1999, 17, $163-168$. [CrossRef]

36. Coyle, J.T.; Puttfarcken, P. Oxidative stress, glutamate, and neurodegenerative disorders. Science 1993, 262, 689-695. [CrossRef]

37. Chen, D.Y.; Bambah-Mukku, D.; Pollonini, G.; Alberini, C.M. Glucocorticoid receptors recruit the CaMKII $\alpha$-BDNF-CREB pathways to mediate memory consolidation. Nat. Neurosci. 2012, 15, 1707-1714. [CrossRef]

(C) 2018 by the authors. Licensee MDPI, Basel, Switzerland. This article is an open access article distributed under the terms and conditions of the Creative Commons Attribution (CC BY) license (http://creativecommons.org/licenses/by/4.0/). 